\title{
Management concept for meadow-soils located downstream to mining dumps
}

\author{
F. Jaenig \\ CDM Consult GmbH, Bochum, Germany
}

\begin{abstract}
The hydrothermal ore deposits of the Harz region have fostered an early development of metal ore mining and the closely linked metallurgy. In the closer Harz region and its proximate foreland the soils are highly enriched with heavy metals due to the emissions of the metallurgy. Through leaching processes and fluvial transport, these particles are enriched in river basins of Oker, Innerste, Leine, and Aller in the form of watery solutions or bound to suspended particles (so-called the "Harz-problem"). Floodwater events of these rivers lead to sedimentation in the wet lands, which partially show high concentrations of heavy metals - especially, arsenic, cadmium, copper, lead and zinc. Concentrations, which limit the human usage of these soils and waters, are common.

For a consistent record and assessment of the contaminated areas by heavy metal a field mapping with regard to usage and a probing concept of the affected river area was created. On this basis a declaration of areas with equal heavy metal potentials and an assessment of the areas with regard to an action plan was carried out.

Keywords: heavy metals, meadow-soils, metallurgy, soil and groundwater pollution, soil-development plan.
\end{abstract}

\section{Introduction}

Since the $3^{\text {rd }}$ century the hydrothermal ore deposits of the Harz region have fostered the development of metal ore mining and the closely linked metallurgy. In the closer Harz region and its proximate foreland the soils are highly enriched with heavy metals due to the emissions of the metallurgy and its mine dump. Through leaching processes and fluvial transport these particles are enriched in 
river basins of Oker, Innerste, Leine, and Aller in the form of watery solutions or bound to suspended particles (so called: "Harz-problem"). Floodwater events of these rivers lead to sedimentation in the bet lands, which partially show high concentrations of heavy metals - especially arsenic, cadmium, copper, lead and zinc. Fluvial material of the mine dump is being transported and reallocated, as to form a substantial part of meadow sedimentation and enriches locally to secondary deposit [1]. Resulting from these heavy metal concentrations in these certain areas are being recorded, which pose a hazard to humans, fauna and flora [1]. By that death of livestock, which has grazed on the meadows, death of water birds, as well as lower crop yields in farming has been observed repeatedly in the past [1].

Since the existing heavy metal concentrations can only be removed with high effort, depending on the circumstances [1], working groups within the rural district have been formed to consistently compile and assess the areas of heavy metal contamination, in order to establish action recommendations, such as limitations of usage and consumption advice etc.

Hereafter an anonymous example in which the procedure of such an area assessment of one of the rural districts in question is presented.

\section{Description of the investigation area}

The area under investigation encompasses a section of a river, which is prone to the "Harz problem". On both sides of the river, which runs at a height of about $+59.00 \mathrm{~m} \mathrm{SL}$, the slopes increase within a short distance to $+63.50 \mathrm{~m} \mathrm{SL}$, $65.00 \mathrm{~m} \mathrm{SL}$, respectively. The meadow area is mainly being used as permanent grassland. Farm and forest land is located in higher areas.

The area of investigation near the surface is shaped by quaternary sedimentation, which are typical for the recent flood plain as well as the historic river basin: In the area of the recent and historic river basin typical meadow sediments occur below the humus top soil horizon. The meadows sediments are characterised by a few centimetres up to a few metres of heavy meadow loam and fine to middle grain sized alluvial sand. These have formed in the Holocene and are still forming today through periodic flooding of the river valleys and neighbouring river basins. Underneath the layer of Holocene meadow loam and sand more than tenths of metres of voluminous Pleistocene lower terrace sand are situated. These are characterised by coarse grained fine and middle sands, which may show intrusions of charcoal or lignite.

Seen from the soil sciences, the influence of the river has lead to a formation of Gleyic sands and Albeluvsols. In the higher situated slopes one finds pod sols and brown soil as well as the corresponding transition soils.

\section{Investigations}

At first a utilisation mapping of the entire river system was performed, which was based on existing GIS data of the different public authorities and institutions. Hereby it was possible to verify the usage of each of the plot area 
beforehand. Additionally, a map of the potential and historic flooding areas during different flood levels was constructed, in order to survey the potential of heavy metal sedimentation. A thorough description of the utilisation map and the determination of the flooding areas is not given at this point.

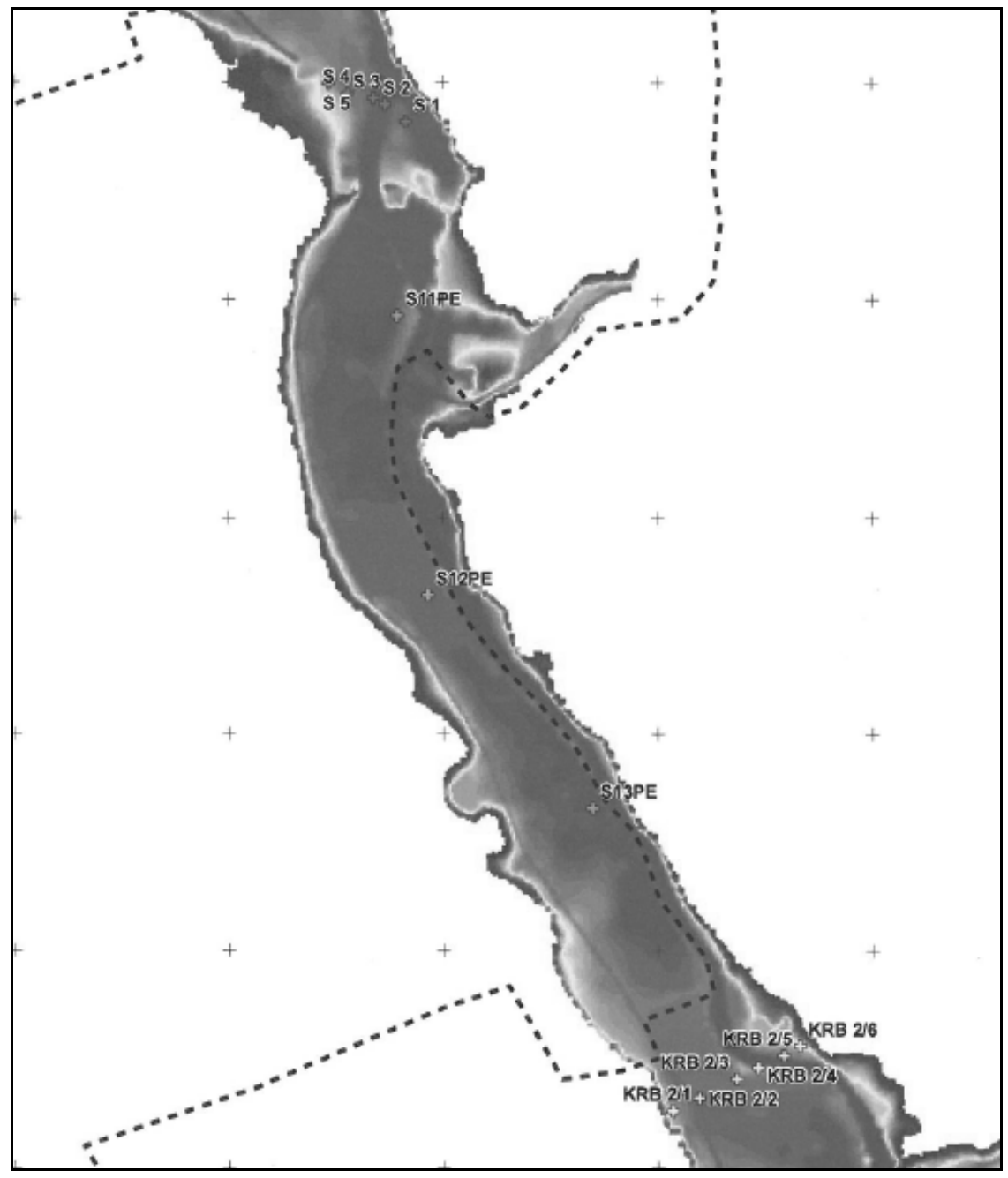

Figure 1: Illustration of the drill holes and catenas in the plan for potential flooding.

In a second step the probe-taking concept was developed, which enabled a rendering of the exposed soil types in the different flooding areas according to their heavy metal concentration and thereby giving a rendering for the usage of the area. The probe-taking concept included the exploration of the soil with regard to its geophysical structure, its physico-chemical composition, as well as 
its heavy metal contamination. In this the locations of probing where especially selected according to the sensitive areas of the problem at hand. Coined as "sensitive" where such areas, in which the intake of heavy metals in the food chain could not be excluded. These were, for instance, farm lands, on which crops for human consumption or live stock feed for meat stock was produced, pasture area for meat stock or residential areas with kitchen gardens and playgrounds for small children.

On this basis several probes have been borne vertically to the river along two catenas within the exploration area as well as additional single probes for the final area distinction (see figure 1).

The probes have been borne into the field until a depth of max. $2 \mathrm{~m}$, followed by geological and soil-scientific attention. For each soil horizon a soil probe was taken and chemically analysed for the heavy metals arsenic, cadmium, copper, lead, zinc, mercury, nickel and chromium. Additionally the organic concentration for selected soil probes was determined and the fine grain proportion $<63 \mu \mathrm{m}$ and the $\mathrm{pH}$ evaluated.

\section{Results}

In the preparation of the soil development plan it was on the one hand necessary to take into account the effect of the heavy metal concentration to plant growth and to look at the direct (through live stock) and indirect (through animal produce) consumption of plants. Furthermore, the handling of soil during potential constructions had to be assessed. In Germany it is mandatory to take different regulations into account.

\subsection{German rules and standards}

For the assessment of the quality of the plants and by that the contamination-free intake of plants by humans and animals or of animal produce respectively the federal soil protection and contamination ordinance (BBodSchV) [2] is being used. In this - among others - the influencing pathways of the soil-crop assessment and measurement values for the different benefit scenarios is determined.

Moreover in [2] the assessment values of the influencing pathways soilhuman in different kinds of usage is indicated. Table 1 shows the values, which are necessary in the assessment.

In the determination of the heavy metal contamination in the usage "farm land/kitchen garden" two analytical methods are to bear in mind. On the one hand the heavy metals through aqua regia digestion (AR) and on the other hand the ammonium nitrate digestion (AN) has to be investigated. Through this method it is possible to differentiate for one thing the total heavy metal concentration (AR) and for another thing the plant-accessible proportion (AN). 
Table 1: Assessment and measurement values for the influencing pathways soil-crop and soil-human.

\begin{tabular}{|c|c|c|c|c|}
\hline \multirow{2}{*}{ Substance } & \multicolumn{4}{|c|}{ Assessment and measurement values } \\
\cline { 2 - 5 } & $\begin{array}{c}\text { Farm land/ } \\
\text { kitchen gardens }\end{array}$ & Method & Grassland & $\begin{array}{c}\text { Park recreational } \\
\text { areas }\end{array}$ \\
\hline \multirow{3}{*}{ Arsenic } & 200 & KW & & 125 \\
& $50^{1)}$ & KW & 50 & \\
\hline Cadmium & $0.4^{2)}$ & AN & & 50 \\
\hline Lead & 0.1 & AN & 20 & 1,000 \\
\hline Mercury & 0.1 & AN & 1,200 & 50 \\
\hline Copper & 5 & KW & 2 & no value \\
\hline Nickel & 1.5 & AN & $1,300^{4)}$ & 350 \\
\hline Zinc & 2 & AN & 1,900 & no value \\
\hline
\end{tabular}

${ }^{1)}$ For soils with partially reduced conditions.

${ }^{2)}$ Farm land.

${ }^{3)}$ On areas of bread wheat cultivation or cultivation of vegetables with high cadmium levels.

${ }^{4)}$ For usage through sheep a concentration of $200 \mathrm{mg} / \mathrm{kg}$ is applicable.

In Germany soil, which is for instance waste of earthworks, has to be processed through disposals. Depending on the degree of contamination this earth excavation can be used in other processes under certain circumstances or has to - in case of exceeding the values - be disposed on a landfill for construction waste. For such an assessment with regard to the waste disposal the LAGA [3] is being used. Soil with values of $\mathrm{Z0}$ are declared to be clean and can be reused without restrictions. Soils with values of 1 and 2 can be reused under certain safety measures. Soils with values above $\mathrm{Z} 2$ have to be disposed on a landfill. Table 2 shows the values, which are needed in the assessment.

Table 2: $\quad$ Values of LAGA.

\begin{tabular}{|c|c|c|c|}
\hline \multirow{2}{*}{ Substance } & \multicolumn{3}{|c|}{$\begin{array}{c}\text { Values } \\
{[\mathbf{m g} / \mathbf{k g}]}\end{array}$} \\
\cline { 2 - 4 } & $\mathbf{Z 0}$ & $\mathbf{Z 1}$ & $\mathbf{Z 2}$ \\
\hline Arsenic & 10 & 45 & 150 \\
\hline Cadmium & 0.4 & 3 & 10 \\
\hline Lead & 40 & 210 & 700 \\
\hline Mercury & 0.1 & 1.5 & 500 \\
\hline Copper & 20 & 120 & 500 \\
\hline Nickel & 15 & 150 & 1,500 \\
\hline Zinc & 60 & 450 & \\
\hline
\end{tabular}




\subsection{Geology/pedology}

The probes of the middle and south region of the area of investigation meadow loam of a maximal volume of $1.40 \mathrm{~m}$ exposed. The main constituent was silt, which was layered with different parts of clay and fine sand. Humus components and larger plant parts (roots) are found especially in the upper horizons up to $0.20 \mathrm{~m}$, and locally in higher depths of $0.80 \mathrm{~m}$. Beneath the meadow loam fluvial fine and middle sand is being found, which in the north of the area of investigation can be found directly on the surface. Near-surface these sands show elements of humus.

Pedologically, all soils show to a greater or lesser extent the distinct influence of the meadow dynamics of the river: Because of the sedimentation of fine grained and humus sediments it is expected to observe a high sorption potential of cat ions from the exchanger of the organic substances and on the clay minerals. According to the specific locality and milieu dependent formation the soils were classified as regosol-gley, norm-vega and meadow gley.

\subsection{Heavy metal concentrations}

Exemplary for the three probes S11, S12 and S13, see figure 1, the determined results of the chemical analysis are in parts presented in table 3.

Table 3: Data of the heavy metal concentration, concentrations of organic substance and concentration of fine grain material.

\begin{tabular}{|c|c|c|c|c|c|c|c|c|c|}
\hline \multirow[t]{2}{*}{$\mathrm{N}^{\mathrm{o}}$} & As & $\mathrm{Cd}$ & $\mathrm{Pb}$ & $\mathrm{Zn}$ & $\mathrm{C}_{\text {org }}$ & $\begin{array}{l}<63 \\
\mu \mathrm{m}\end{array}$ & $\mathrm{pH}$ & Application & $\begin{array}{l}\text { Flooding } \\
\text { during } \\
\text { river } \\
\text { water } \\
\text { increase }\end{array}$ \\
\hline & \multicolumn{4}{|c|}{$[\mathrm{mg} / \mathrm{kg}]$} & {$[\%]$} & {$[\%]$} & - & & {$[\mathrm{m}]$} \\
\hline S11/1 & 21 & 24 & 300 & 1,390 & 8.0 & 22.5 & 6.5 & \multirow{4}{*}{ Grass land } & \multirow{4}{*}{$0.1-0.2$} \\
\hline S11/2 & bdl & 0.52 & 19 & 190 & 0.5 & 5.5 & 6.8 & & \\
\hline S11/3 & 4.7 & 6.2 & 25 & 1,710 & - & - & - & & \\
\hline S11/4 & 1.8 & 2.5 & 15 & 2,030 & - & - & - & & \\
\hline $\mathrm{S} 12 / 1$ & 28 & 14 & 340 & 1,250 & - & - & - & & \\
\hline $\mathrm{S} 12 / 2$ & 71 & 8.1 & 1,420 & 1,810 & - & - & - & Grass land & $0.3-0.4$ \\
\hline S13/1 & 24 & 10 & 430 & 1,300 & 14.6 & 19.5 & 6.3 & & \\
\hline $\mathrm{S} 13 / 2$ & 14 & 0.93 & 47 & 420 & 3.8 & 31.1 & 6.4 & Gracs land & 4 \\
\hline $\mathrm{S} 13 / 3$ & 5.2 & 0.23 & 8.9 & 65 & - & - & - & Urass Iand & $0.3-0.4$ \\
\hline S13/4 & bdl & bdl & 3.5 & 22 & - & - & - & & \\
\hline
\end{tabular}

bdl = below detection limit.

- = no analysis.

italics $=$ exceedings of the LAGA Z2 value.

bold black $=$ exceedings of BBodSchV grass land usage. 


\subsection{Heavy metal setting}

From the observed results it is not possible to determine a clear distribution pattern of heavy metal concentrations with regard to the local characteristics of the uncovered soil and soil milieu. Although it is possible to correspond certain local heavy metal distributions to specific characteristics of the soil, these single event interpretations do not allow generalizations. Looking at figure 2 , it is made clear that the highest heavy metal concentrations and the highest heavy metal spectrum is being uncovered by probe $\mathrm{S} 2$. In this area the $\mathrm{pH}$ of all soil layers lies between 7.1 and 7.3 in the neutral regime. Since the solubility of heavy metals with a $\mathrm{pH}<6$ increases in the ranking $\mathrm{Pb}(4.0-3.5)<\mathrm{Cu}(4.5)<\mathrm{Ni}(5.5)<$ $\mathrm{Zn}(5.3-6.0)<\mathrm{Cd}(6.5)$, a high adsorption of heavy metals at the adsorbents in the soil is observed with increasing $\mathrm{pH}$. The investigation results show, that in an interpretation of the inhomogeneous heavy metal distribution in the area of investigation at least for cadmium, zinc and mercury the $\mathrm{pH}$ threshold can significantly be considered.

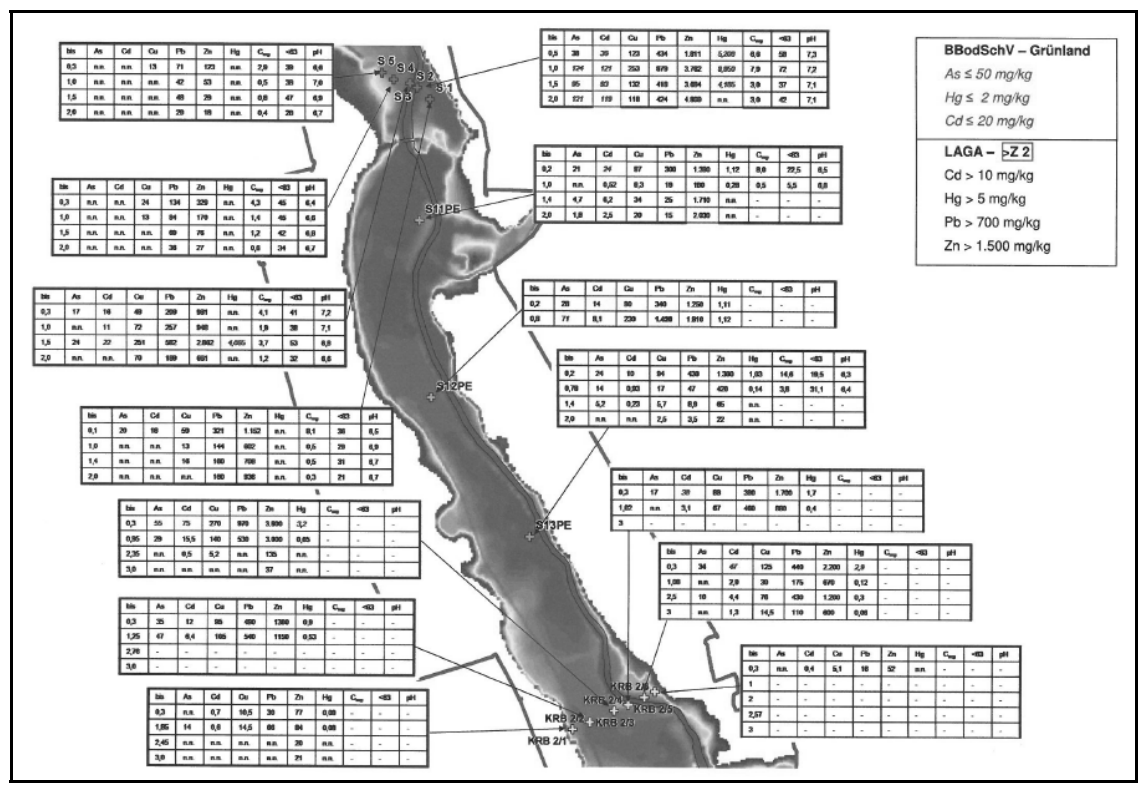

Figure 2: Representation and assessment of the results according to BBodSchV/LAGA.

However, in the whole assumptions for the heavy metal concentrations cannot be made on the basis of locality/characteristics of the drill point. Moreover the resulting heavy metals are due to interchanges of various factors: Fine grain proportion and organic concentration of the soil pose crucial factors, which codetermine the potential heavy metal concentration of a soil through their adsorption potential. However, this takes place in dependence of the soil milieu. 
The soil milieu is influenced through its soil type as well as the likelihood of flooding, the time span and frequency of flooding, respectively. The time span of flooding is for its part is given through morphology and roughness of the surface.

Hence, despite similar characteristics marked deviations in the heavy metal budget are observed in the area of investigation, see figure 2 .

\section{Soil development-plan}

As a matter of priority the area of investigation is assessed with regard to the grass land usage, since at the time of investigation the meadow area was exclusively used as grass land and fallow.

For an assessment of the influencing pathway soil-human the value figures of BBodSchV, see table 1, for "park and recreational areas" can be consulted, as these correspond to the fallow usage. The soil investigations illustrate, that up to a depth of $0,30 \mathrm{~m}$ the usage of the meadows is possible without posing hazards to the human health, since the usage is similar to the "park and recreational area". The lower soil layers surpass the significant values by far.

With regard to the influencing pathway soil-crop areas were designated, which were according to the investigation results not usable as grass land, see figure 3. In compliance with BBodSchV [2] areas, which up to a depth of $0.10 \mathrm{~m}$ exceed the value figure for grass land, see table 1 . This is the case in the area of probe S2, S11, as well as KRB2/3, KRB 2/4 and KRB 2/5. The designation of areas also took into account the exceeding of value figures for grass land in

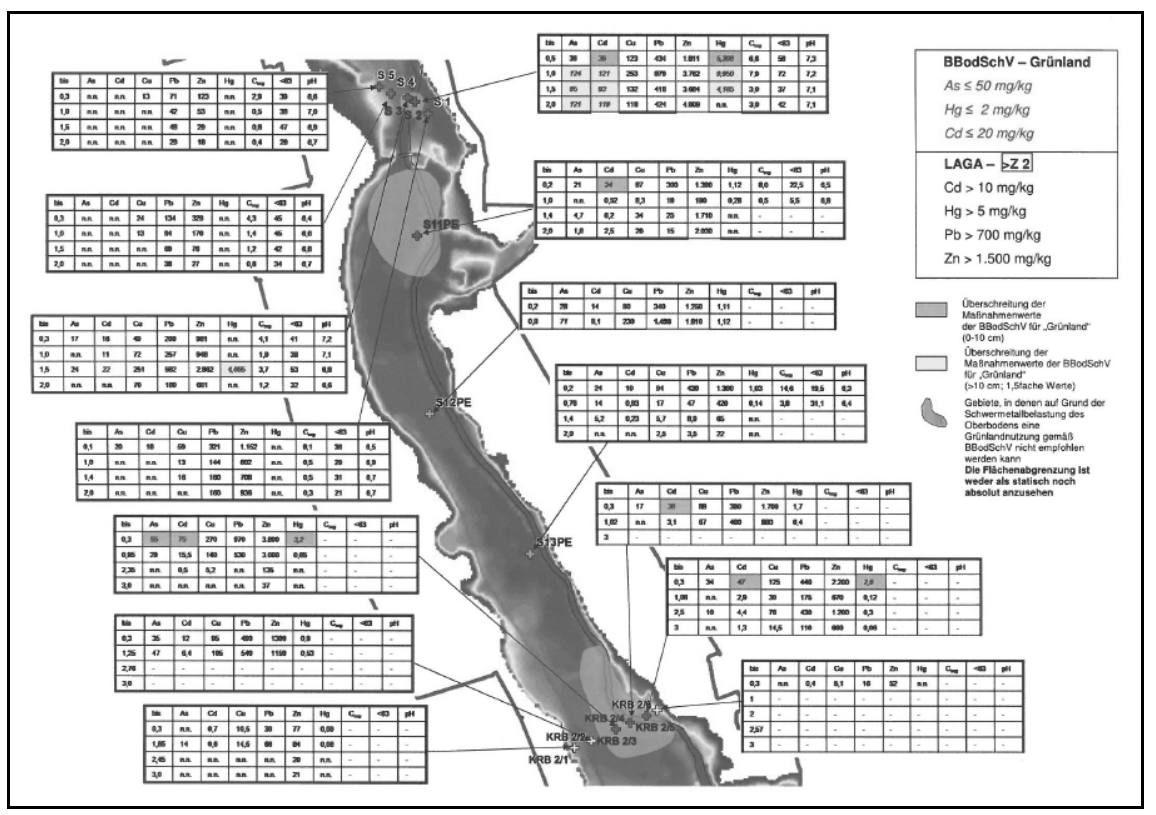

Figure 3: Declaration of areas suitable for grass land use. 
lower soil regions, such as was recorded for S4, as well as morphological structures. Thereby the areas have been broadened, since the surrounding shows similar macro and micro structures, which could result in similar heavy metal contaminations.

According to BBodSchV [2] grass land usage encompasses - amongst others - the grazing by live stock. This means, that on these areas, which are declared for grass land usage, dairy cattle as well as meat stock may graze and hay of these areas may be used as fodder without posing hazards to the products.

It is not without questions that on the identified areas, where the heavy metal concentrations have exceeded the value figures for grass land usage, the heavy metals may reach into the food chain causing hazards to animals and humans. This is why one should refrain from using these areas as grass land or grazing of animals, which are not the product or part of a product of the food chain (i.e. horses). Likewise the utilisation of plants (grass, hay etc.) should not be fed to meat stock.

The conversion of usage of the land, which is usable as grass land, to more sensitive utilizations such as farm land or kitchen gardens is not recommended. The heavy metal distribution in the area of investigation is very inhomogeneous and generally it is expected to observe higher concentrations of heavy metal in the surface layers of the meadow areas that are prone to flooding.

\section{Conclusions}

The investigations show that meadows can be used as recreational areas, since the sojourn of the human, without significant interference with the ground, poses no health threat. Solely during excavations, shoreline and riverbed works and similar works, in which direct contact with highly contaminated soils is not ruled out, safety measures are - if necessary - to be taken, for instance wearing gloves. Likewise the waste disposal costs may arise from soil excavations.

Furthermore, it was shown in the investigation that, except for a few areas, the meadows are generally usable as grass land. Meeting the value figures of BBodSchV [2] ensures grazing by live stock and/or the production of fodder/hay on these areas to pose no health threat to humans or animals through intake of such products.

Nevertheless, heavy metals can also be solved in the form of suspended matter and transported as attachment with the river water, a fact which is to be considered. In flooding events suspended particles can settle and accumulate externally on the surface of plants. Through this way heavy metals can be consumed during grazing and potentially enter the food chain. In order to minimize the hazard potential areas of flooding should not be grazed or mowed directly after a flooding event or used only by animals, which are not part of the food chain, not as product nor as part of a product.

In areas, which are not usable as grass land, it is not excluded that additionally to pollutant accumulation after flooding events also a transfer of heavy metals from the soil to the plant is taking place. Therefore a usage as grass land could pose a hazard. Hence, one should refrain from this utilization or 
corresponding usage (grass or hay), or grazing by animals, which are not a product or part of a product for the food chain, respectively.

All in all the declaration of areas should not be seen as static or absolutely, much rather as a result of an interpolation with technical interpretation. Therefore it is not to be ruled out, that in the areas of investigation there are certain parts with differentiating extent, which have higher or lower heavy metal contaminations. Furthermore, the declaration is temporary, since the sedimentation milieu is continuously changing due to the river dynamics (flooding intervals/ - times/and - time spans) and hence the heavy metal accumulation changes.

\section{Acknowledgement}

I thank the administrative district concerned for the permission of publication.

\section{References}

[1] Knolle, F., Auswirkungen des Mineral- und Gesteinsabbaus im Westharz Das Beispiel der montaninduzierten Schwermetallbelastung und des geplanten Teilabbaus des Iberges, Arbeitsgemeinschaft für Karstkunde Harz e.V., http://www.karstwanderweg.de/publika/ahdn/31/218-220/index.htm

[2] Der Bundesminister für Umwelt, Naturschutz und Reaktorsicherheit, Berlin: Bundes-Bodenschutz- und Altlastenverordnung (BBodSchV), BGB1. I S. 1554, 12. July 1999.

[3] Länderarbeitsgemeinschaft Abfall (LAGA): Anforderungen an die stoffliche Verwertung von mineralischen Reststoffen/Abfällen: Teil II: Technische Regeln für die Verwertung 1.2 Bodenmaterial (TR Boden); November 2004.

[4] Landkreis Goslar Gesundheitsamt, Hinweise und Empfehlungen zur Bearbeitung und Nutzung schwermetallkontaminierter Gartenböden Anbau- und Verzehrempfehlungen, Goslar, 01/2005. 